\title{
Plastic Syringe
}

National Cancer Institute

\section{Source}

National Cancer Institute. Plastic Syringe. NCI Thesaurus. Code C43204.

A device for the administration of parenteral drug products that consists of a rigid plastic barrel fitted with septum with a plunger at one end and a seal or needle at the other end. The needle assembly may be part of the device or separate. 